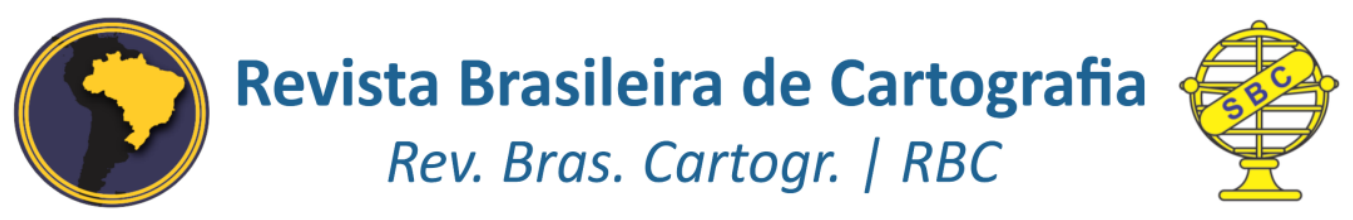

DOI: http://dx.doi.org/10.14393/rbcv71n2-45150

\title{
Mapeamento da Vulnerabilidade de Evacuação em Caso de Desastres Naturais Empregando a Sintaxe Espacial
}

Mapping the evacuation vulnerability in case of natural disasters employing the space syntax

\author{
Gustavo Medeiros de Pinho ${ }^{1}$ \\ Leonardo Castro de Oliveira ${ }^{2}$ \\ Marcos de Meneses Rocha ${ }^{3}$ \\ Ana Paula Borba Gonçalves Barros 4
}

Recebido em outubro de 2018. Aprovado em maio de 2019.

\begin{abstract}
RESUMO
Na ocorrência de Desastres Naturais, uma das formas de diminuir as perdas humanas é a realização da evacuação de pessoas. A evacuação consiste na retirada das pessoas de suas moradias para um lugar considerado seguro, procedimento este que pode ser realizado antes da materialização do desastre ou no momento de sua ocorrência. A pesquisa tem por objetivo propor uma metodologia para o mapeamento da vulnerabilidade de evacuação em caso de desastres naturais. Pretende-se avaliar o quão vulnerável uma comunidade está para a realização de uma evacuação. Considera-se que a evacuação é influenciada por diversos fatores, dentre os possíveis fatores optou-se por selecionar: a qualidade de vida que se encontram os indivíduos (vulnerabilidade social), a quantidade de pessoas a serem evacuadas na área (densidade demográfica) e a qualidade das vias por meio da sua integração (medida pela Sintaxe Espacial). A partir desses três condicionantes, propõem-se a criação de um indicador de vulnerabilidade de evacuação onde cada setor possui um valor entre 0 e 1 , onde 1 é o setor com maior vulnerabilidade e 0 o de menor vulnerabilidade. O estudo de caso foi feito no município de Nova Friburgo, tendo por principal resultado a vulnerabilidade de evacuação seguindo um padrão centroperiferia, onde o centro da cidade apresenta as melhores condições de vida, baixa exposição e vias mais integradas.
\end{abstract}

\footnotetext{
${ }^{1}$ Programa de Pós-graduação em Engenharia Cartográfica, Instituto Militar de Engenharia, Brasil. Email: gmpinho@gmail.com

2 Programa de Pós-graduação em Engenharia Cartográfica, Instituto Militar de Engenharia, Brasil. Email: leonardo@ime.eb.br

${ }^{3}$ Programa de Pós-graduação em Engenharia Cartográfica, Instituto Militar de Engenharia, Brasil. Email:mrocha@ime.eb.br

${ }^{4}$ Programa de Mestrado em Arquitetura e Urbanismo, Centro Universitário de Brasília, Brasil. E-mail: anapaulabgb@.com
} 
PALAVRAS-CHAVE: Evacuação. Vulnerabilidade. Desastres naturais. Sintaxe espacial.

\begin{abstract}
In case of Natural Disasters, one of the ways of reducing human loss during the occurrence of this phenomenon is performing an evacuation of people. The evacuation consists in removing people from their housing to a place considered safe, procedure that can be done before or during the event. This study aims to develop a methodology for mapping evacuation vulnerability in case of natural disasters. It is intended to evaluate how much vulnerable a community is to execute an evacuation. Evacuation is influenced by several factors, it was decided to select the following among all of them: the quality of individuals' life (social vulnerability), the amount of person to be evacuated (demographic density) and the quality of routes through their integration (measured by spatial syntax).From those conditioning factors, it was created an index of evacuation vulnerability assigning values from 0 to 1 , where 1 is the sector with greater vulnerability and 0 the sector with less vulnerability. The case study was made in the city of Nova Friburgo, the evacuation vulnerability, in general, follows a center-periphery pattern, where the city center presents better living conditions, low exposure and more integrated routes.
\end{abstract}

KEYWORDS: Evacuation. Vulnerability. Natural hazards. Space syntax.

$$
* * *
$$

\title{
Introdução
}

A relação entre homem e natureza nem sempre tem consequências positivas, por muitas vezes o homem ocupa locais com características de risco sem qualquer planejamento ou infraestrutura que dê conta das adversidades. Os fenômenos naturais fazem parte da dinâmica natural da Terra, mas ao atingirem populações, causando algum tipo de perda ou prejuízo, resultam em acidentes que, em algumas proporções, tornam-se desastres. Nas últimas décadas foram verificados o aumento na recorrência de desastres naturais no mundo e no Brasil, com marco significativo no desastre natural da região serrana do Rio de Janeiro em 2011.

No Brasil, mais de $80 \%$ da população reside em áreas urbanas com ocupação desordenada (IBGE, 2010), expondo fragilidades das sociedades, com diferenciações na escala intraurbana, seja em características de exposição e dificuldade de acesso a serviços, seja na capacidade de responder 
aos impactos de origem natural. É nesse contexto que o estudo e identificação da vulnerabilidade das comunidades é essencial para serem traçadas políticas públicas urbanas de caráter preventivo, com objetivo de redução de perdas humanas (ANAZAWA, 2012).

Com a prevenção como guia, a evacuação é uma ação que visa retirar pessoas de áreas mais suscetíveis a ocorrência de fenômenos naturais consideradas perigosas, para a realocação em áreas seguras (CASTRO, 2008). A evacuação é uma ação complexa que exige um planejamento bem consolidado para que sua eficiência atinja o seu principal fim que é salvar vidas. Como parte do planejamento da evacuação, está a identificação da vulnerabilidade, traçando um perfil da população e da área a ser evacuada, auxiliando na orientação de ações prévias que irão consolidar as rotas de fuga e outras ações a serem tomadas (JAFARI et al., 2003).

Como instrumento essencial para o planejamento urbano, os mapas de vulnerabilidade permitem a identificação de padrões de distribuição espacial das diversas variáveis que possam influenciar na vulnerabilidade de uma população. Com isso, a vulnerabilidade relacionada à evacuação pode ser mapeada e ser analisada pela utilização de indicadores que padronizam valores da exposição física e da capacidade de resposta das pessoas, do número de evacuados e da forma urbana e de seus graus de integração e acessibilidade. Para isso, lançou-se da utilização dos Sistemas de Informação Geográfica (SIG) que, por suas características, permite integrar dados de diversas fontes em banco de dados georreferenciados (CAMARA e MEDEIROS, 2003).

A presente pesquisa tem por objetivo propor uma metodologia para o mapeamento da vulnerabilidade de evacuação de pessoas em áreas urbanas em caso de desastres naturais provocados por movimentos de massa. Esta proposta baseia-se na construção de indicadores que permitam inferir sobre a qualidade da vida das pessoas e a integração das vias, que uma vez combinados, formam o indicador de vulnerabilidade de evacuação a ser mapeado. 
O processo de planejamento da evacuação no Brasil, previsto na Política Nacional de Proteção e Defesa Civil (2012), carece de uma metodologia robusta que preveja a utilização de diferentes variáveis para o mapeamento de rotas de fuga e disponibilização de pontos de apoio e sirenes de alerta. A partir de reuniões realizadas ao longo da pesquisa com gestores públicos e agentes de defesas civis municipais, verificou-se que a evacuação muitas vezes é planejada apenas a partir do conhecimento de alguns agentes o qual pode estar eivado de erros e limitações, fruto da subjetividade e limitação da capacidade humana de lidar com a complexidade de tantos fatores envolvidos em um desastre natural. Com o intuito de oferecer suporte confiável ao trabalho das pessoas que arriscam suas vidas para o auxílio dos afetados e vítimas, esta pesquisa pretende contribuir neste planejamento, identificando vulnerabilidades da população em áreas urbanas frente a necessidade de uma evacuação.

\section{Metodologia para o Mapeamento da Vulnerabilidade de Evacuação}

A vulnerabilidade é um conceito utilizado nas mais diferentes áreas do conhecimento. Em cada uma delas ganha alguma pequena diferenciação em sua definição e fatores que a compõem, além de um adjetivo específico dependendo da disciplina que a está estudando (WISNER, 2009). Em sua natureza plural de inúmeras facetas e dimensões, a quantificação, a qualificação e a espacialização da vulnerabilidade são extremamente complexas, mas de fundamental importância (SZLAFSZTEIN, 2015). Como chama atenção Braga et al. (2006), mensurá-la significa integrar um grande número de informações e para isso é necessário a produção de indicadores.

No entanto, para a vulnerabilidade de evacuação, objeto desta pesquisa, não foram encontrados indicadores que relacionem a qualidade de vida das pessoas nem a integração e acessibilidade das vias. Com isso, para esta pesquisa, a vulnerabilidade de evacuação - definida como o grau de dificuldade que uma população possui de realizar uma evacuação frente as 
suas realidades sociais e de infraestrutura viária (COVA e CHURCH, 1997) - será analisada a partir das seguintes componentes: a vulnerabilidade social; o número de pessoas; e a integração das vias.

A vulnerabilidade social envolverá as características sociais (escolaridade, renda, idade e gênero) e de acesso aos serviços (água, esgoto, luz e lixo) e se restringirá a áreas urbanas municipais. O número de pessoas será retratado pela densidade demográfica, caracterizando a quantidade de pessoas a serem evacuadas. A integração das vias corresponde à distribuição espacial das vias, a qual representa a movimentação das pessoas, a ser medida pelo índice de integração proposto pela Sintaxe Espacial (SE).

Para cada componente da vulnerabilidade de evacuação, foram criados indicadores padronizados, possibilitando que os mesmos fossem agregados em uma unidade de planejamento. São eles: o indicador de vulnerabilidade social; a densidade demográfica; e o de integração das vias. A combinação desses indicadores gera o indicador de vulnerabilidade de evacuação, representando a dificuldade que a população possui frente a uma ação de evacuação. $O$ indicador tem como principal objetivo subsidiar modelos que representem a realidade, conciliando a simplicidade de uso e a facilidade de transmissão da informação a ser utilizada no planejamento da evacuação de pessoas (CONFALONIERI et al. 2015). Cada indicador, com seus respectivos mapas, aponta para um ou mais problemas que estão influenciando na vulnerabilidade de evacuação, seja ele, nas variáveis sociais ou de integração das vias. Com acesso a todos os indicadores o planejador poderá trabalhar efetivamente com a causa principal que está dificultando a evacuação das pessoas.

A área urbana de um município é considerada, nesta pesquisa, como a área composta pelos setores censitários classificados como urbanos e que possuam maior concentração da população municipal. Estes serviram ainda como unidades de análise para a produção do mapeamento da vulnerabilidade de evacuação. Os setores censitários são a menor unidade de coleta estatística para a divulgação de dados do censo demográfico no Brasil (IBGE, 2014). A 
utilização destes como unidade de análise para a coleta de dados e aplicação do método permite uma avaliação detalhada na escala intraurbana.

\subsection{Indicador de Vulnerabilidade Social - IVS}

A vulnerabilidade social é entendida nesta pesquisa como as características sociais que influenciam o processo de evacuação, seja pelo grau de exposição dos indivíduos, seja pela capacidade de resposta aos fenômenos naturais extremos. A escolha das variáveis procurou traçar um perfil das condições de vida dos indivíduos, visando não só indicar uma maior exposição aos impactos e efeitos de um desastre natural, mas também de apontar para dificuldades no enfrentamento e recuperação. Para tanto, foram produzidos indicadores individuais para cada variável no intuito de revelar as condições críticas da população, assim como as condições domiciliares e de acesso a serviços básicos.

A exposição dos indivíduos está caracterizada nas variáveis ligadas à qualidade dos domicílios e acessos a serviços básicos de fornecimento de água, energia elétrica, coleta de lixo e esgotamento sanitário. As variáveis utilizadas foram retiradas do universo de variáveis do Censo Demográfico do Brasil 2010 (IBGE, 2010).

Saito (2011) observa que o abastecimento de água por rede geral possui maior qualidade e contribui para uma melhor estrutura da casa, sendo a melhor forma de acesso à água, evitando ligações improvisadas, que podem gerar escoamento superficial, saturação do solo e contaminação dos lençóis freáticos, fatos que podem contribuir para a ocorrência de escorregamentos.

A melhor condição para a variável esgotamento sanitário é a ligação direta à rede pública. As outras formas, como fossas, valas e céu aberto, são reconhecidas como potencializadoras da ocorrência de escorregamentos, facilitando a erosão das encostas e taludes, assim como a saturação do solo (SAITO, 2011; MIRANDOLA e MACEDO, 2014; ALHEIROS, 2003; CARVALHO et al., 2007; ARMESTO, 2012). 
Em relação à energia elétrica foram considerados como maior vulnerabilidade a daqueles domicílios que não são ligadas às companhias de distribuição, que não possuem relógio próprio, utilizam energia de fontes alternativas e os domicílios sem energia. Essas características podem levar "a população a procurar outros meios, como as ligações informais, que poderiam vir a ocasionar curtos circuitos e consequentes incêndios" (SAITO, 2011).

O lixo coletado por serviço de limpeza e em caçamba por serviço de limpeza aparecem como as melhores condições dos domicílios. As outras formas de destinação do lixo são consideradas como potencializadoras de maior exposição das pessoas, uma vez que é reconhecido o papel do lixo não destinado corretamente na desestabilização de encostas (MIRANDOLA e MACEDO, 2014; SAITO, 2011).

A capacidade de resposta aos fenômenos naturais extremos, ou seja, as dificuldades para o enfrentamento e recuperação estão ligadas, principalmente: a) ao entendimento e compreensão dos sinais de alerta e de evacuação; b) a noção de risco que estão expostos; c) ao próprio processo de recuperação pós-desastre; d) a exposição física do indivíduo. Nesse sentido, estão caracterizadas neste trabalho pelas variáveis renda, idade, escolaridade e gênero.

A renda é uma variável importante para a capacidade de resposta e recuperação para os afetados por um desastre natural. A mesma pode influenciar na obtenção de serviços básicos assim como na qualidade da moradia e local de instalação do domicílio (WISNER et al., 2004). A falta de rendimento, ou o baixo rendimento (menor que um salário mínimo), dificulta os indivíduos a obterem recursos destinados a salvaguardar suas vidas, seus bens e prover os meios de subsistência, além de se recuperarem mais lentamente após o desastre, sendo que sua renda pode dificultar o restabelecimento de uma situação de normalidade (SAITO, 2011; TORRES, 2000; NEUMAYER e PLÜMPER, 2007; MARANDOLA e HOGAN, 2005; WISNER et al., 2004). 
A idade da população deve ser considerada, pois entende-se que, em se materializando a evacuação, as diferentes faixas etárias irão reagir de formas sensivelmente diferentes, principalmente os extremos da pirâmide etária, crianças e idosos. Para Liu et al. (2002) as crianças não seriam capazes de reagir adequadamente como os adultos quando expostos a um desastre. Wisner et al. (2004) ainda chama atenção que os idosos podem apresentar maior dificuldade de locomoção autônoma, o que dificultaria sua mobilidade em uma evacuação.

Segundo o relatório do Marco de Sendai (UNITED NATIONS, 2015), mulheres e crianças foram afetadas de formas desproporcionais em relação aos demais grupos. Como analisado por Eklund e Tellier (2012), a mortalidade e a morbidade em decorrência dos desastres naturais afetam mais as crianças e as mulheres. A questão do gênero também é importante e muitas vezes é computado para a interpretação da vulnerabilidade de uma população.

Diversos autores apontam a relação da escolaridade com a questão do gênero, entendendo que a educação, em particular da mulher, é o maior fator social e econômico associado à redução da vulnerabilidade a desastres naturais (STRIESSING, LUTZ e PATT, 2013). Trabalhos como os de Blankespoor et al. (2010) e Wamsler, Brink e Rentala (2012) identificam que o investimento na educação formal e igualdade de gênero na educação contribuem e desempenham papel fundamental na determinação do nível de vulnerabilidade das pessoas, e apontam que as mulheres com maior nível de instrução contribuem no aumento da renda e diminuem esta vulnerabilidade.

A escolaridade é um aspecto de suma importância para a capacidade de resposta da população, assim como da adaptação frente a um potencial desastre (WASMLER et al., 2012). Considera-se que os mais escolarizados por possuírem maior instrução, tem maior facilidade de compreensão de alertas, interpretação e identificação da sinalização de evacuação e também na identificação de ameaças (SAITO, 2011). Esta variável ainda estaria ligada à variável renda, pois uma vez maior a escolaridade da pessoa maior a possibilidade de garantir uma renda mais adequada. 
Sintetizando, a menor capacidade de resposta fica caracterizada por indivíduos do sexo feminino, com idades menores que 6 anos e maiores que 60 anos, pessoas não alfabetizadas ou com menos de 5 anos de estudos e com renda abaixo de 1 salário mínimo. As outras situações, portanto, indicam uma melhora na capacidade de resposta e exposição física dos indivíduos e contribuem para reduzir a vulnerabilidade social.

\subsubsection{Construção dos Indicadores Sociais}

Após identificar as variáveis, verificam-se as possíveis fontes destas informações e o nível de agregação a ser empregado. Estes dados costumam estar presentes nos Censos Demográficos e o nível de agregação mais detalhado possível seria, nesse caso, os setores censitários. Definidas as variáveis que caracterizam a vulnerabilidade social, foram criados indicadores individuais para cada uma, com objetivo de identificar os setores censitários que se encontram em estado crítico em cada informação da vulnerabilidade social. Os indicadores individuais são produzidos a partir da equação (1):

$$
\mathrm{Iv}=\frac{\text { Condições de maior vulnerabilidade }}{\text { Número de Habitantes }}
$$

onde o valor Iv é o valor final para cada variável em questão e n corresponde cada variável. São somados os números de moradores em condições de maior vulnerabilidade em cada variável, e dividindo esta soma pelo número de moradores de cada setor censitário. Com isso, cada setor ganha uma nota entre 0 e 1 , onde o valor 1 identifica a pior condição de vulnerabilidade e o valor 0 a melhor condição de vulnerabilidade (SENA, 2015), obtendo-se dessa forma indicadores normalizados de cada variável.

Para a construção do indicador ficou estabelecido que o mesmo seria a média aritmética dos indicadores temáticos em cada setor, de acordo com a equação (2): 


$$
\frac{(I v A+I v E s+I v L+I v E+I v R+I v I+I v E d+I v G)}{8}
$$

onde o IvA é o indicador de abastecimento de água; IvEs é o indicador de acesso ao esgotamento sanitário; IvL é o indicador de destinação do lixo; IvE é o indicador de acesso a rede elétrica; IvR o indicador de renda; IvI o indicador da idade; IvEd indicador de escolaridade e IvG o indicador de gênero.O IVS de cada setor censitário é padronizado para valores entre 0 e 1 segundo a equação (3):

$$
\text { IVS }=\frac{(\text { IVdosetor }- \text { menorIV })}{(\text { maiorIV }- \text { menorIV })}
$$

onde IVS é o valor padronizado do indicador de vulnerabilidade social e IV os valores individuais de cada setor. Os setores classificados como 1 são os de maior vulnerabilidade social e os mais próximos ao 0 são os com menor vulnerabilidade social. Os valores intermediários são indicadores de maior, média ou menor vulnerabilidade, função de estarem mais próximos dos extremos. Não foram introduzidos pesos nas diferentes variáveis tratadas neste indicador, considera-se que todas as variáveis contribuem com igual importância, e "que o próprio resultado do cálculo representa as condições em que se encontra o setor censitário, variando entre 0 e 1” (SENA, 2015).

Chama atenção que muitos trabalhos que envolvem a temática da evacuação costumam utilizar somente os dados de densidade demográfica e de infraestrutura viária, como Cova e Church (1997) e Alberico et al. (2012), sem a consideração das características sociais de exposição e capacidade de resposta. O cálculo da densidade é produzido a partir da divisão entre o número de moradores, dado adquirido no universo do Censo 2010 (IBGE, 2010), pela área em quilômetro quadrado do setor censitário (equação 4) e padronizada pela equação (3):

$$
I D D=\frac{\text { Número de moradores }}{\text { Área em } \mathrm{km}^{\wedge} 2 \text { do setor }}
$$


onde IDD é o indicador de densidade demográfica e os setores classificados como 1 são os de maior densidade e os mais próximos ao 0 são os com menor densidade.

\subsection{Indicador de Integração de Vias - IIV}

A produção do Indicador de Integração de Vias (IIV) se baseia nas premissas da Teoria da Sintaxe Espacial (SE), que tem como principal objetivo estudar o relacionamento entre o espaço construído (edifício ou a cidade) e a sociedade (HOLANDA, 2002). Esta relação se dá pela investigação e análise da forma urbana, procurando-se avaliar o movimento de pessoas e veículos no espaço, a partir ou resultante dessa configuração espacial.

Buscou-se avaliar a forma urbana enquanto facilitador ou não dos movimentos na área urbana, a fim de serem caracterizadas áreas que auxiliam ou dificultam a evacuação. $O$ método segue os aspectos técnicos da SE para a produção das linhas axiais que compõe o mapa axial, a fim de se obterem os índices de integração (Rn) das vias.

Posteriormente, estes índices foram transferidos para os setores sociais, por um método, a ser explicado a seguir, e o valor final foi escalonado para se ter o IIV entre 0 e 1 , onde 1 representa os piores casos de integração e 0 os melhores casos.

Ao se trabalhar a forma urbana na SE, utiliza-se a representação da malha viária por meio de eixos lineares, obtidas pelo traçado do menor número possível das maiores retas que representam os acessos diretos da trama urbana (BARROS, 2014; MEDEIROS, 2006).

Conhecidos como linhas axiais, estes segmentos de retas devem sempre se cruzar e, a partir do traçado de todas as linhas axiais em uma região geográfica de interesse (a exemplo da cidade de Maringá, na Figura 1), é possível gerar uma matriz de interseção que, ao ser analisada, gera valores representativos das relações entre estas feições (BARROS, 2014; MEDEIROS, 2006; HOLANDA, 2002; HILLIER, 1996; HILLIER e HANSON, 1984). 
Figura 1 - a) Representação Linear da cidade de Maringá - PR; b) Mapa Axial da cidade de

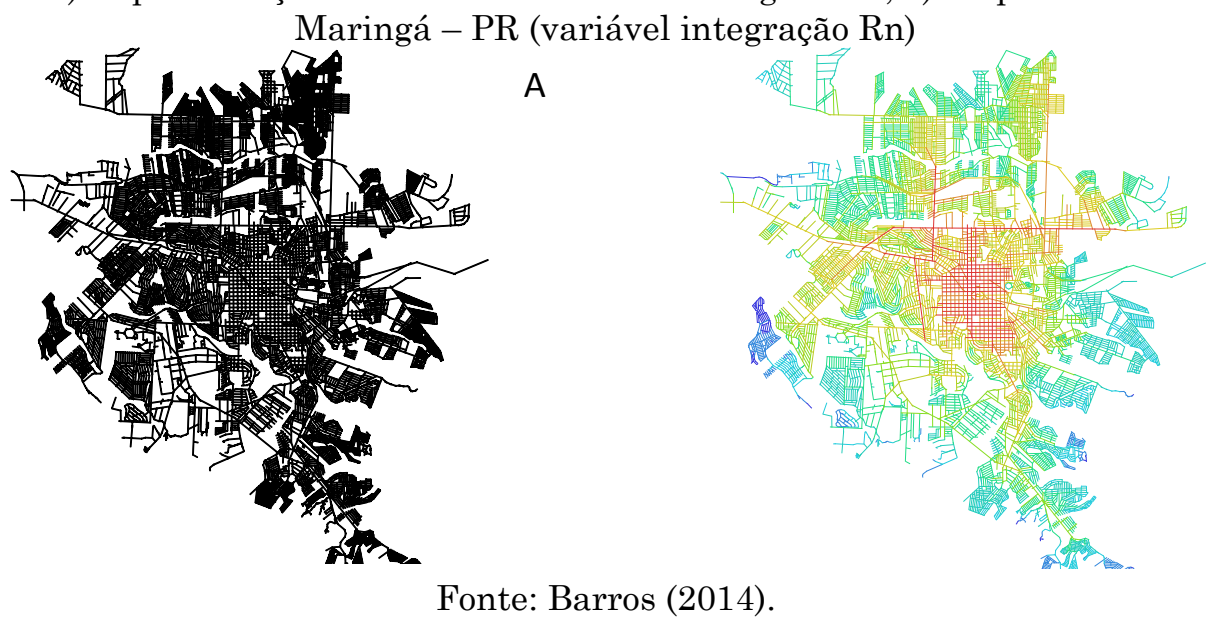

B

O valor obtido por meio do índice de integração é o potencial de ou acessibilidade $(\mathrm{Rn})$ de todos os eixos viários para todos os eixos viários do sistema (grande porte/cidades ou pequeno porte/bairros) estudado, traduzindo o potencial de atração de fluxos de movimento de cada eixo para a trama urbana que está sendo investigada (BARROS, 2014).

O mapa é simbolizado em uma escala cromática variando das cores quentes às frias, onde os eixos mais integrados são vermelhos, passando pelos tons de laranja, verde e azul, até chegar aos eixos de menor integração, em azul escuro (Figuras 1 e 2). Esta simbologia permite a identificação visual tanto dos eixos mais acessíveis e integrados quanto dos de menores valores, bem como da interpretação da disposição espacial dos mesmos, identificando áreas segregadas e núcleos integradores.

A busca por eixos de maior potencial de integração, no contexto de uma evacuação, configura a melhor situação que se pode encontrar, uma vez que estes apresentam maior possibilidade de acessibilidade, ao passo que vias mais segregadas caracterizam uma maior complexidade na movimentação de pessoas para um local seguro, na ocorrência de movimentos de massa.

Cabe ressaltar que o mapa não necessariamente representa o movimento real, pois lhe falta a composição de outras variáveis definidoras do mesmo (como atrativos econômicos, características geométricas das vias 
etc.), mas sim o potencial da geração de movimento que uma trama urbana pode possuir (BARROS, 2014).

Baseando-se nos trabalhos de Medeiros (2006), Turner (2004), Barros (2006), Barros (2014) e Gil (2015), são apresentadas a seguir as etapas do método manual para a produção das linhas axiais e mapas axiais e como os mesmos foram produzidos nesta pesquisa.

A partir da base cartográfica de uma cidade, segmentos de linha foram produzidos retratando os eixos das vias, os quais passam a ser denominados de linhas axiais. Os polígonos que representam as áreas construídas ou quarteirões, onde não serão avaliados os fluxos, devem ser fechados e apenas se utiliza o espaço que representam as vias (Figura 2.a). Considerando que devem ser produzidos o menor número das maiores linhas possíveis, permitese que os segmentos de reta sejam delimitados sem necessariamente coincidir com os eixos das vias (Figura 2.b). Devem ser aplicadas regras topológicas para que se certifique que todas as linhas axiais se toquem. Nos mapas axiais da SE é comum que sejam vistos os segmentos de retas extrapolando os limites das vias, como apresentado na Figura 2.c. As linhas axiais finalizadas se apresentam como a Figura 2.d, na qual estas foram traçadas sobre as vias da Figura 2.a.

Figura 2 - a) Vias do centro de Nova Friburgo representadas pelas faces de quadra; b) Linha axial não seguindo o eixo exato da via; c) Forma padrão de desenho das linhas axiais para assegurar que as linhas se toquem; d) Linhas axiais sobre as vias do Centro de Nova Friburgo

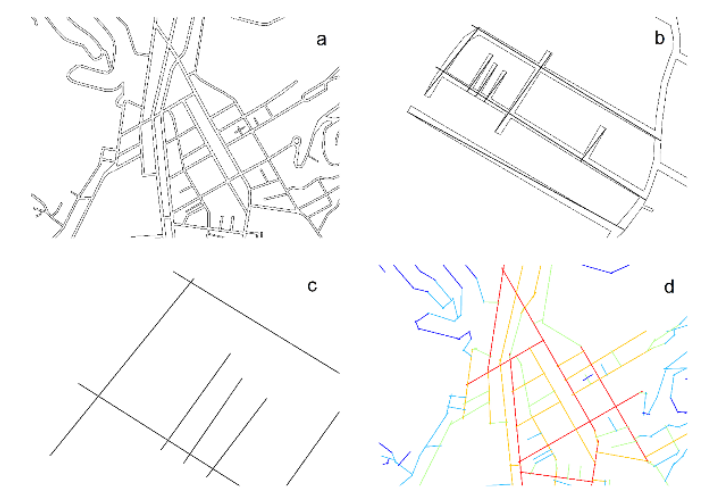

Fonte: Elaborada pelos autores. 
Como representação da forma urbana foram utilizadas as quadras e as faces de quadra do IBGE, onde as quadras "são, geralmente, uma área retangular bem definida da zona urbana limitada por ruas e/ou estrada, contudo, pode ter forma irregular e ser limitada por elementos como estradas, cursos d'água ou encostas" e as faces de quadra são "um dos lados da quadra, contendo ou não domicílios" (IBGE, 2010). Estas bases vetoriais fornecem uma base de logradouros (ruas, avenidas, praças, jardins etc.) compatíveis com os setores censitários do censo demográfico (IBGE, 2016), auxiliando na descrição do espaço urbano. Estas podem ser substituídas por qualquer base cartográfica digital da cidade que se queira trabalhar.

Depois de construídas as linhas axiais, devem ser feitas as correções topológicas, para em seguida serem feitas as análises. Para as correções topológicas se utiliza a extensão QGis Space Syntax Toolkit (GIL, 2015), que permite a análise sobre a topologia, além de uma interação com o software DepthmapX, software de análise dos dados da SE. Os dois juntos permitem trabalhar o método da SE em um ambiente SIG, possibilitando que outras operações espaciais sejam realizadas. Foi utilizada uma rotina de verificação e correção da integridade topológica das linhas axiais (GIL, 2015). A função de correção topológica do QGis Space Syntax Toolkit possui os parâmetros que atendem a SE, e busca erros comuns na produção manual das linhas axiais, como: linhas pequenas com menos de 1 metro; linhas com mais de um nó; linhas com pontos coincidentes; feições duplicadas; linhas curtas (o ponto final da linha está perto de outra linha, mas não há interseção); linha órfã (não faz interseção com nenhuma linha); e ilhas, grupo de linhas desconectados do mapa principal.

Após serem realizadas as correções topológicas, ainda no ambiente SIG, o software DepthmapX possibilita o cálculo, por meio da conectividade das linhas axiais, do índice de integração de cada segmento, considerando o sistema como um todo ou em um raio local. O índice de integração de cada segmento é associado à tabela de atributos do dado geográfico e visualizado 
em uma escala de cor, seguindo as premissas da $\mathrm{SE}$, onde o vermelho representa segmentos mais integrados, passando por laranja, verde, azul claro, até o azul escuro, que representa os segmentos menos integrados.

Nessa modelagem foi utilizado o mapa axial produzido com raio topológico R3 (HILLIER e HANSON, 1984)), que correspondem ao índice local de análise. Barros (2014) identifica que estudos comprovam que a utilização do R3 coincide com as propriedades potenciais locais de movimentação. Outro motivo para a utilização do índice local R3 é a velocidade dos movimentos de massa do tipo corrida, escorregamentos e queda de blocos, uma vez que essa característica exige rápida movimentação em curto espaço de tempo, normalmente associada a distâncias curtas, mais locais.

Para a criação do IIV foi necessário aplicar um método que fosse capaz de transferir os dados da integração para os setores censitários que segue o fluxo apresentado na Figura 3.

Figura 3 - Fluxograma apresentando o método para calcular o IIV de cada setor censitário

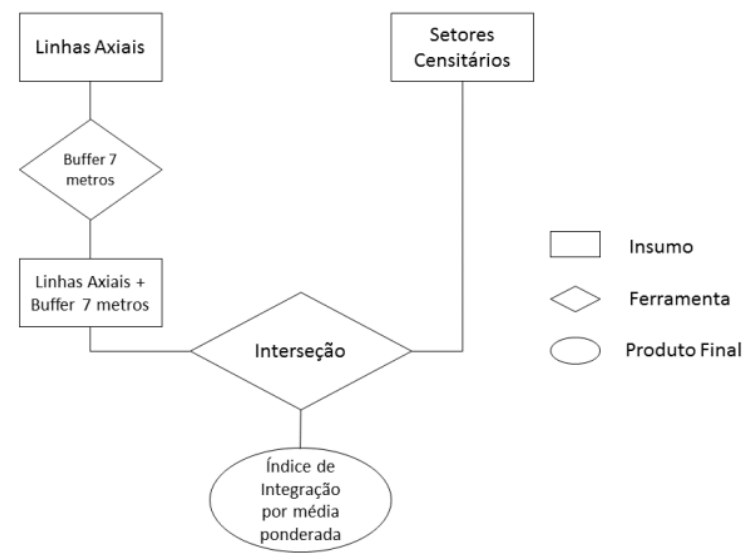

Fonte: Elaborada pelos autores.

Foi feita uma classificação das vias em 5 classes pelo método das quebras naturais, onde cada classe ganhou um valor entre 1 e 5 , onde 1 corresponde as linhas axiais mais integradas e 5 para as menos integradas, passando pelas outras classes (Tabela 1). 
Tabela 1 - Intervalo das 5 classes de integração e seus respectivos pesos

\begin{tabular}{c|c}
\hline $\begin{array}{c}\text { Intervalos de } \\
\text { Integração }\end{array}$ & Pesos por classe \\
\hline $0,33-0,89$ & 5 \\
\hline $0,89-1,45$ & 4 \\
\hline $1,45-2,01$ & 3 \\
\hline $2,01-2,57$ & 2 \\
\hline $2,57-3,13$ & 1 \\
\hline
\end{tabular}

Fonte: Elaborada pelos autores.

A partir desta classificação propõe-se que os valores para cada setor serão a média ponderada das classes e extensão das vias nas quais o determinado setor possui acesso direto. Por acesso direto entende-se as vias que estão até 7 metros de todas as direções de um determinado setor. Este valor foi escolhido, com o intuito de que sejam selecionadas, ao menos, duas faixas de rolamento com largura em torno de 3 metros.

Este procedimento foi realizado no software Arcgis, através da plataforma de construção de modelos (ModelBuilder), que por ser uma linguagem de programação visual, permite a construção de fluxos de trabalho de geoprocessamento. Foram realizados os seguintes passos: para as linhas axiais já tratadas pelo DepthmapX, contendo seus valores de integração, é produzido um buffer de 7 metros para todas as direções de cada linha axial; utilizando esse buffer realiza-se uma interseção entre o polígono do buffer e os setores censitários. Esta operação resulta em quais valores de integração de cada linha a sete metros correspondem a um setor em interseção. Desse modo, cada setor passa a possuir mais de um valor de integração por fazer interseção com mais de uma via. Para se ter um valor único desta integração em cada setor, propõe-se a realização de uma média ponderada destes índices por suas classes e a soma dos comprimentos, segundo a equação (5):

$$
I I V=\frac{\sum_{\mathrm{i}=1}^{\mathrm{n}}\left(\mathrm{P}_{\mathrm{i}} \mathrm{x}_{\mathrm{Ext}_{\mathrm{i}}}\right)}{\sum_{\mathrm{i}=1}^{\mathrm{n}} \mathrm{Ext}_{\mathrm{i}}}
$$

onde IIV é o valor do indicador para cada setor, $P i$ o valor dado a cada classe, variando de 1 a 5, e Exti é a extensão em metros de cada linha axial que faz 
interseção com o setor. As classes correspondem diretamente aos valores computados pela SE. A escolha pela utilização do comprimento foi o entendimento que, apesar de uma via ser pouco integrada, ela pode ter um comprimento que seja ótimo para o fluxo de pessoas de um lugar não seguro para um lugar seguro. Por fim, os valores, utilizando a mesma ideia da equação (3), do IIV são padronizados entre os valores de 0 e 1 para utilização no indicador final de vulnerabilidade de evacuação.

\subsection{Indicador de Vulnerabilidade de Evacuação - IVE}

O indicador de vulnerabilidade de evacuação é composto pelos três indicadores anteriores. Tem o propósito de retratar as dificuldades que uma população pode enfrentar ao ser evacuada frente a um perigo eminente ou já materializado. Para o indicador leva-se em consideração a vulnerabilidade social das pessoas, que refletem suas qualidades de vida, a quantidade de pessoas a serem evacuadas e a integração das vias, representando a facilidade ou não de movimento na forma urbana. A partir dos resultados obtidos nas etapas anteriores, o cálculo do IVE foi feito a partir da seguinte equação (6):

$$
\operatorname{IVE}=\frac{(I V S+I D D+I I V)}{3}
$$

onde o IVE é o valor do indicador de vulnerabilidade de evacuação, o IVS o indicador de vulnerabilidade social, o IDD o indicador da densidade demográfica e o IIV o indicador de integração das vias para cada setor censitário da área de estudo. Com esta equação, os setores que possuem IVE $=1$ correspondem as áreas com maior vulnerabilidade de evacuação e o os setores com IVE = 0 são aqueles com melhor situação em relação a evacuação de pessoas em caso de desastres naturais. Esta proposta entende que todas as três situações influenciam de maneira igual na evacuação das pessoas e não pretende de forma alguma avaliar quais dos fatores mais influenciam o processo de evacuação de pessoas. 


\section{Estudo de Caso: Nova Friburgo - RJ}

Destaca-se para esta pesquisa o município de Nova Friburgo, com um total de 420 mortes e uma concentração do maior número de ocorrência de movimentos de massa deflagrados dentre todos os atingidos pelo desastre de 2011 (DOURADO et al. 2012). O município está na porção da Serra do Mar denominada como Serra dos Órgãos, inserida na unidade geomorfológica Planalto do Reverso da Serra dos Órgãos (DANTAS, 2001). A população está concentrada em uma pequena porção do município e está localizada, segundo a Figura 4, pelo limite em vermelho. Está delimitada pelos setores censitários classificados como urbanos totalizando 158.663 habitantes, aproximadamente $87 \%$ da população total do município.

Figura 4- Mapa de Localização do município de Nova Friburgo, com destaque em vermelho para os setores censitários da área de estudo

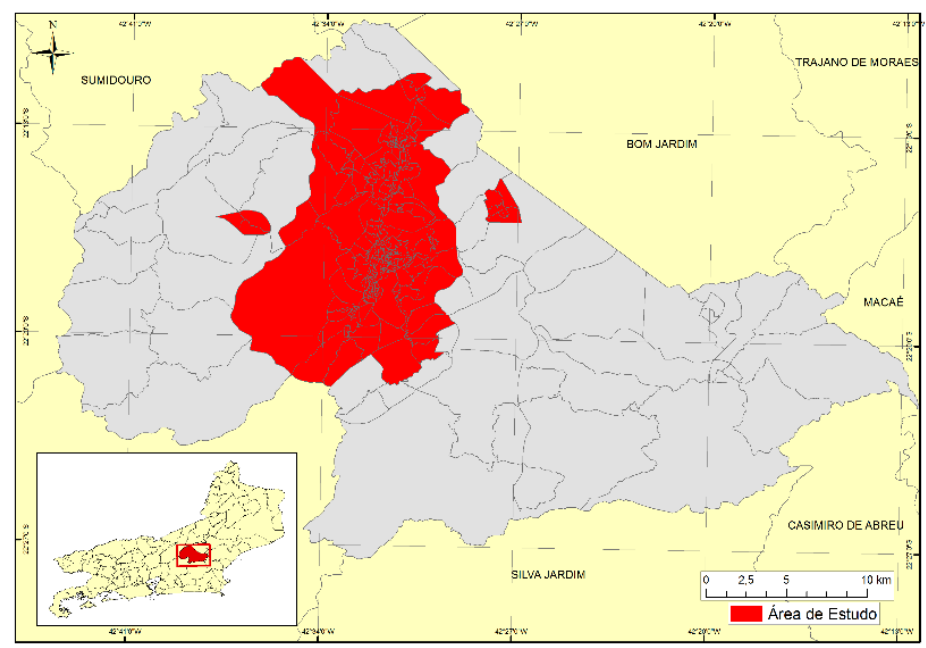

Fonte: Elaborada pelos autores.

\subsection{Vulnerabilidade Social}

Após a aplicação do IVS tem-se como resultado o mapa da Figura 5. Para a classificação do IVS foi utilizado o método de quebras naturais em 5 classes, muito baixa, baixa, média, alta e muito alta, caracterizando a vulnerabilidade social. No mapa está representada a vulnerabilidade social 
muito alta em tons de marrom escuro e a vulnerabilidade social muito baixa em tons mais claros.

Figura 5- Mapa da Vulnerabilidade social

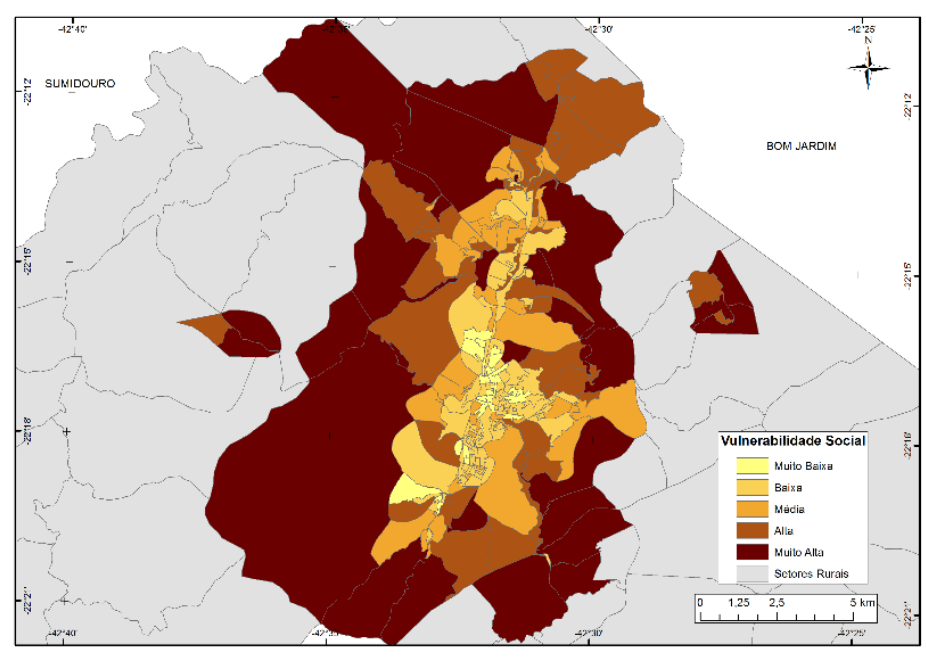

Fonte: Elaborada pelos autores.

É possível observar que a área central da área de estudo concentra os setores de baixa ou muito baixa vulnerabilidade social e pela Tabela 2 , podese perceber que $45,76 \%$ da população vive nestes setores (130 setores censitários), em um total de 72.611 moradores. A cidade apresenta um padrão de centro para periferia em relação às condições sociais, que pioram gradativamente quando se distancia da região central.

Tabela 2 - Vulnerabilidade Social

\begin{tabular}{c|c|c|c}
\hline $\begin{array}{c}\text { Classes de } \\
\text { vulnerabilidade }\end{array}$ & $\begin{array}{c}\mathbf{N}^{\mathbf{o}} \text { de } \\
\text { setores }\end{array}$ & $\begin{array}{c}\text { População } \\
\text { em setores } \\
\text { censitários }\end{array}$ & $\begin{array}{c}\text { \% de } \\
\text { população }\end{array}$ \\
\hline Muito Baixa & 31 & 14954 & 9,43 \\
\hline Baixa & 99 & 57657 & 36,34 \\
\hline Média & 53 & 36729 & 23,15 \\
\hline Alta & 50 & 31282 & 19,72 \\
\hline Muito Alta & 30 & 18041 & 11,37 \\
\hline Total & 263 & 158.663 & 100 \\
\hline
\end{tabular}

Fonte: Elaborada pelos autores. 
Com isso, a vulnerabilidade social é maior nas áreas periféricas, com 31,09\% da população, somando 80 setores censitários e 49.323 habitantes em situações de alta ou muito alta vulnerabilidade. Sendo destes, aproximadamente $11,4 \%$ em situação de vulnerabilidade muito alta, com 18.041 habitantes em condições de maior exposição e menor capacidade de resposta. Estes setores correspondem às áreas mais segregadas socialmente, e no geral estes setores possuem características parecidas com as classificadas como aglomerados subnormais (IBGE, 2014).

A população da área de estudo encontra-se principalmente concentrada nas áreas centrais da cidade, junto ao rio Bengala e ao trecho da RJ-116, principal acesso à cidade. A maior densidade se dá em apenas um dos setores e 8,78\% da população se encontra em setores com alta densidade demográfica, sendo estas duas classes concentradas principalmente no eixo da RJ-116 (Tabela 3 e Figura 6).

Tabela 3 - Densidade Demográfica

\begin{tabular}{c|c|c|c}
\hline $\begin{array}{c}\text { Classe de } \\
\text { densidade }\end{array}$ & $\begin{array}{c}\mathbf{N}^{\mathbf{o}} \text { de } \\
\text { Setores }\end{array}$ & $\begin{array}{c}\text { População } \\
\text { em setores } \\
\text { censitários }\end{array}$ & $\begin{array}{c}\text { \% de } \\
\text { população }\end{array}$ \\
\hline Muito Baixa & 105 & 65725 & 41,42 \\
\hline Baixa & 74 & 44593 & 28,11 \\
\hline Média & 61 & 34238 & 21,58 \\
\hline Alta & 22 & 13934 & 8,78 \\
\hline Muito Alta & 1 & 173 & 0,11 \\
\hline Total & 263 & 158663 & 100 \\
\hline \multicolumn{3}{c}{ Fonte: Elaborada pelos autores. }
\end{tabular}


Figura 6 - Mapa da densidade demográfica

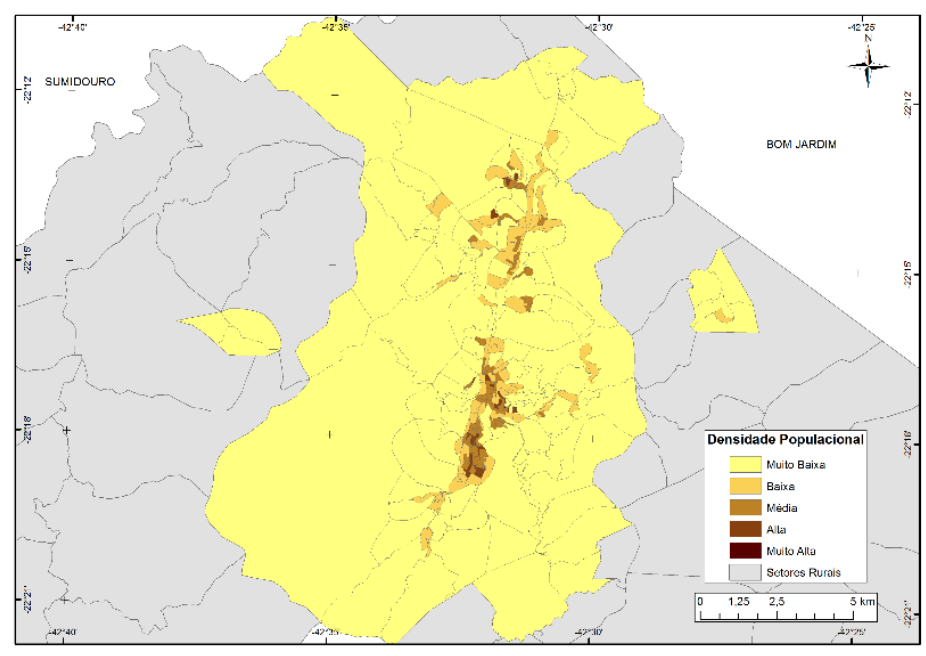

Fonte: Elaborada pelos autores.

Assim como o mapa de vulnerabilidade social, o mapa de densidade demográfica está dividido em 5 classes por quebras naturais, caracterizando as piores condições (densidade muito alta) em tons de marrom escuro e as melhores condições (densidade demográfica muito baixa) em tons de marrom claro. Nesta região central, caracterizada pela maior densidade, apresenta-se um padrão construtivo vertical, principalmente de prédios e condomínios fechados. Além disso, se concentram nesta região a oferta de lojas de comércio, serviços e centro administrativo da cidade.

Com o distanciamento do centro e das principais vias de acesso à cidade, a densidade demográfica cai drasticamente, com um aumento de áreas com características de moradia e serviço local e de áreas de ocupação informal (DUARTE, 2009). Isso se deve, principalmente, ao histórico de ocupação da cidade nos fundos de vale e que se utiliza das características geográficas da região para instalar sua infraestrutura urbana. O resultado do mapa de densidade demográfica apresenta esta distribuição espacial e confirma este processo histórico. 


\subsection{Integração de Vias}

No intuito de analisar a forma da cidade como fator que propicia ou não o movimento das pessoas em caso de evacuação utilizou-se, como descrito anteriormente, o mapa axial (Figura 7). Para a área de estudo, o mesmo é composto por 7.679 linhas axiais. Pensando na utilização das vias, principalmente para pedestres, utilizou-se o raio de abrangência local (R3) para o processamento.

Figura 7 - Mapa Axial da área de estudo com destaque para os núcleos de integração da cidade

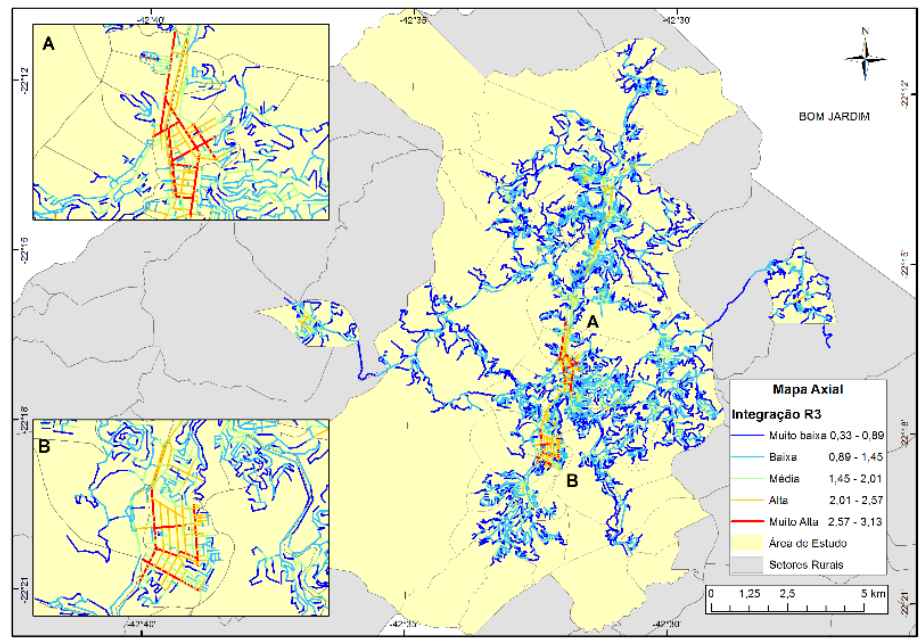

Fonte: Elaborada pelos autores.

A cidade de Nova Friburgo possui um relevo acidentado, característico de áreas urbanas em regiões de serra, apresentando em sua forma de ocupação em uma disposição pouco linear, somente visto nas áreas de fundo de vale, além de apresentar vias muito dispersas, pouco conectadas com a cidade como um todo. Duarte (2009) chama atenção que a configuração natural da região é responsável por esse traçado, uma vez que foi necessário se adaptar às sinuosidades e vales, impostas pelo relevo. Na avaliação da autora, a cidade apresenta dois tipos de configuração: trama formada por 
segmentos retos ortogonais e não ortogonais entre si e trama formada por segmentos retos e curvos acompanhando o relevo da região.

Como principais resultados é possível observar que, nas regiões de fundo de vale mais planas, um traçado mais reto em forma de tabuleiro de xadrez, além de ser possível traçar linhas axiais maiores. Já nas encostas, as vias são mais sinuosas e acompanham o relevo, produzindo linhas axiais mais curtas e, no geral, menos integradas. As linhas axiais são em média de pequenas dimensões, se conectando em poucas linhas, caracterizando uma cidade com baixa integração, característico de estruturas urbanas que apresentam relevo acidentado, como é possível notar nas linhas axiais simbolizadas pelas cores azul claro e escuro. As classes de baixa ou muito baixa integração são a grande maioria, correspondendo a aproximadamente 80\% das vias da cidade (Tabela 4). Essa baixa integração, segundo Holanda (2002) caracterizam uma área urbana de difícil apropriação pelos pedestres, dificultando a circulação. Já a área do centro da cidade permite uma maior apropriação e concentrando as linhas mais integradas.

\begin{tabular}{|c|c|c|}
\hline $\begin{array}{l}\text { Classes de } \\
\text { integração }\end{array}$ & $\begin{array}{l}\text { Linhas } \\
\text { axiais }\end{array}$ & $\begin{array}{l}\% \text { das } \\
\text { linhas } \\
\text { axiais }\end{array}$ \\
\hline Muito Baixa & 3417 & 44,5 \\
\hline Baixa & 3393 & 44,19 \\
\hline Média & 729 & 9,49 \\
\hline Alta & 123 & 1,6 \\
\hline Muito Alta & 17 & 0,22 \\
\hline Total & 7679 & 100 \\
\hline
\end{tabular}

Fonte: Elaborada pelos autores.

A área urbana de Nova Friburgo possui uma quantidade muito baixa de vias com alta e muito alta integração, 140 linhas, sendo apenas 1,82\% do total das linhas axiais do município, correspondendo principalmente ao centro da cidade e imediações. O centro da cidade deveria então ser o local onde deveriam ser alocadas as atividades centrais e de maior importância 
(DUARTE, 2009), sendo uma área de vital importância para a evacuação, possivelmente, como um dos locais ideais para instalação de pontos de apoio. No entanto, esta concentração de vias com altos valores de integração em uma pequena parte da cidade, aponta para a necessidade de se ter pontos de apoio dispersos, atendendo outras localidades. Caso houvesse um bloqueio nesta região central, esta localidade teria o acesso dificultado.

A configuração da cidade de Nova Friburgo proporciona pouca apropriação do pedestre, caracterizado por um sistema pouco integrado. Com isso, a cidade como um todo tem um baixo potencial de movimento, sendo um fator importante para uma cidade com grande recorrência de movimentos de massa, que podem vir a desencadear desastres naturais. Esta configuração, portanto, em sua maioria não facilita a realização da evacuação de pessoas.

Após a avaliação do mapa axial, este foi processado para que os valores de integração fossem atribuídos aos setores censitários, no intuito que estes pudessem ser processados com as outras camadas que compõem a vulnerabilidade de evacuação e o indicador proposto. Cada setor censitário recebe então o valor da média ponderada, pela classe de integração e comprimento do eixo, das linhas axiais que fazem interseção com cada setor. Com isso, é possível determinar áreas com maior ou menor integração, avaliando a acessibilidade de cada setor.

$\mathrm{Na}$ produção do IIV, provindo da média ponderada dos índices de integração das vias, utilizou-se apenas o valor da integração local, uma vez que os deslocamentos em uma evacuação deflagrada por movimentos de massa devem ser rápidos. Após a aplicação do indicador na área de estudo, foi produzido o mapa por setores censitários distribuídos em 5 classes de integração (Figura 8). As classes foram obtidas utilizando as quebras naturais nos valores do IIV para os setores censitários. O mapa da integração das vias apresenta os setores que possuem menor integração representados pela cor marrom escuro, caracterizando as piores condições (integração muito baixa). Para as melhores condições de integração das vias (integração muito alta), os setores estão representados pela cor marrom claro. 
Figura 8 - Mapa da Integração das vias

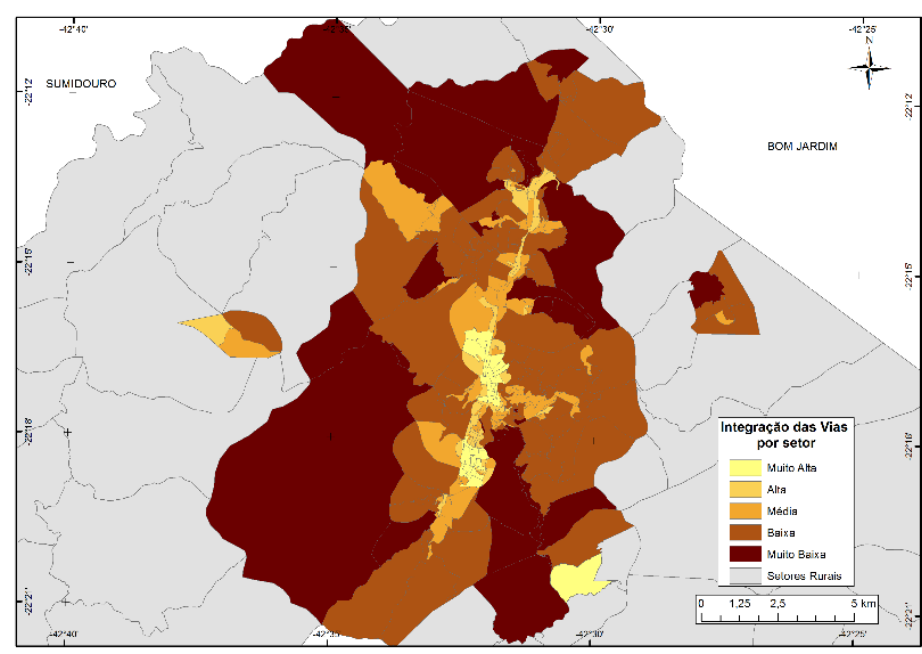

Fonte: Elaborada pelos autores.

Os setores com maior integração das vias estão concentrados na área central da cidade, onde se localizam as vias principais e onde está concentrada a maioria da população, como visto no mapa de densidade demográfica. Em relação a comparação por setores censitários, tem-se que: mais de $30 \%$ da população municipal encontra-se em áreas de alta ou muito alta integração de vias e concentram-se na região central da cidade, somando um total de 49.227 de indivíduos; 45,04\% da população encontra-se em áreas menos integradas e periféricas apresentando um total de 71.463 de moradores (Tabela 5).

Tabela 5 - Integração das Vias

\begin{tabular}{c|c|c|c}
\hline $\begin{array}{c}\text { Classes de } \\
\text { integração }\end{array}$ & $\begin{array}{c}\mathbf{N}^{\mathbf{o}} \text { de } \\
\text { setores }\end{array}$ & $\begin{array}{c}\text { População } \\
\text { em setores } \\
\text { censitários }\end{array}$ & $\begin{array}{c}\text { \% de } \\
\text { população }\end{array}$ \\
\hline Muito Alta & 44 & 25171 & 15,16 \\
\hline Alta & 44 & 24056 & 15,86 \\
\hline Média & 63 & 37973 & 23,93 \\
\hline Baixa & 83 & 55169 & 34,77 \\
\hline Muito Baixa & 29 & 16294 & 10,27 \\
\hline Total & 263 & 158663 & 100 \\
\hline
\end{tabular}

Fonte: Elaborada pelos autores. 


\subsection{Vulnerabilidade de Evacuação}

A aplicação do IVE tem por objetivo mapear os setores censitários avaliados por suas dificuldades frente a realização de uma evacuação. Como visto no capítulo 3 , este indicador é a integração da avaliação da vulnerabilidade social dos moradores, a densidade demográfica e a integração das vias da cidade. Como resultado temos o mapa de vulnerabilidade de evacuação (Figura 9). Assim como os outros mapas, este possui 5 classes divididas por quebras naturais que representam a que nível de vulnerabilidade de evacuação está associado cada setor da área de estudo. As classes de vulnerabilidade são: muito baixa, baixa, média, alta e muito alta, que estão representadas no mapa por uma escala de tons de marrom, onde: os setores com IVE próximos a 1, vulnerabilidade de evacuação muito alta, recebem tons de marrom mais escuros; os setores com IVE próximo a zero, vulnerabilidade de evacuação muito baixa, recebem tons de marrom claro. Os valores intermediários recebem seus tons de marrom em função da proximidade com os extremos.

Figura 9 - Mapa de vulnerabilidade de evacuação

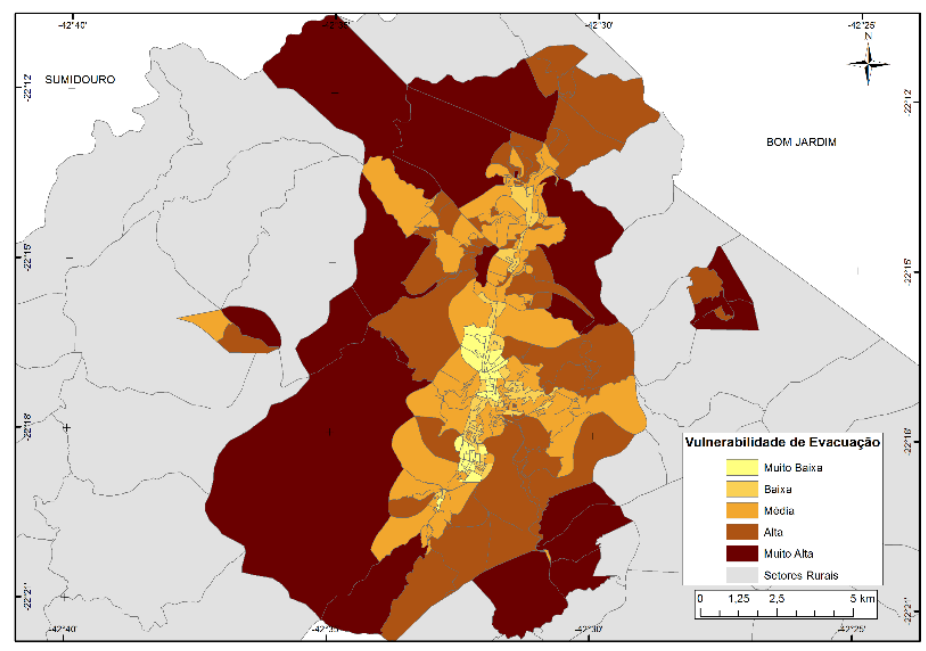

Fonte: Elaborada pelos autores. 
É possível observar um padrão espacial em que as áreas mais centrais, coincidindo com o limite do centro da cidade, possuem uma melhor condição em relação à evacuação, e áreas periféricas, as piores. Cabe ressaltar, que os componentes do indicador foram considerados em igualdade na contribuição e avaliação da vulnerabilidade de evacuação.

A região do centro da cidade apresenta uma concentração de setores de baixa ou muito baixa vulnerabilidade de evacuação, contabilizando 30,33\% da população com um total de 48.123 indivíduos. Saindo do centro em direção das áreas periféricas percebe-se um aumento nos valores do IVE, onde 30,23\% da população, sendo 47.965 indivíduos, estão em áreas de alta e muito alta vulnerabilidade de evacuação. Importante notar que a vulnerabilidade classificada como média concentra quase $40 \%$ da população, num total de 62.575 habitantes (Tabela 6).

Tabela 6 - Vulnerabilidade de Evacuação

\begin{tabular}{c|c|c|c}
\hline $\begin{array}{c}\text { Classe de } \\
\text { vulnerabilidade }\end{array}$ & $\begin{array}{c}\mathbf{N}^{\mathbf{o}} \text { de } \\
\text { setores }\end{array}$ & $\begin{array}{c}\text { População } \\
\text { em setores } \\
\text { censitários }\end{array}$ & $\begin{array}{c}\text { \% de } \\
\text { população }\end{array}$ \\
\hline Muito Baixa & 40 & 21507 & 13,56 \\
\hline Baixa & 48 & 26616 & 16,78 \\
\hline Média & 98 & 62575 & 39,44 \\
\hline Alta & 57 & 37841 & 23,85 \\
\hline Muito Alta & 20 & 10124 & 6,38 \\
\hline Total & 263 & 158663 & 100 \\
\hline \multicolumn{4}{r}{ Fonte: Elaborada pelos autores. }
\end{tabular}

A análise do resultado final permite identificar as áreas com maior vulnerabilidade de evacuação. Como o indicador proposto utiliza uma base de dados única, permite que seus componentes sejam observados, facilitando na avaliação de qual dos fatores influenciou mais ou menos no valor obtido para o IVE de determinado setor. Um valor semelhante no IVE pode apresentar diferentes razões para ter sido classificado como tal, o que permite ao planejador tomar medidas focadas nos problemas que estejam afetando um setor, visando uma melhoria para as condições de realização da evacuação. 
Como exemplo, são selecionados os dois maiores valores identificados pelo IVE no mapeamento realizado, como mostra a Figura 10.

Figura 10 - Mapa com a seleção dos dois setores de maior valor no IVE

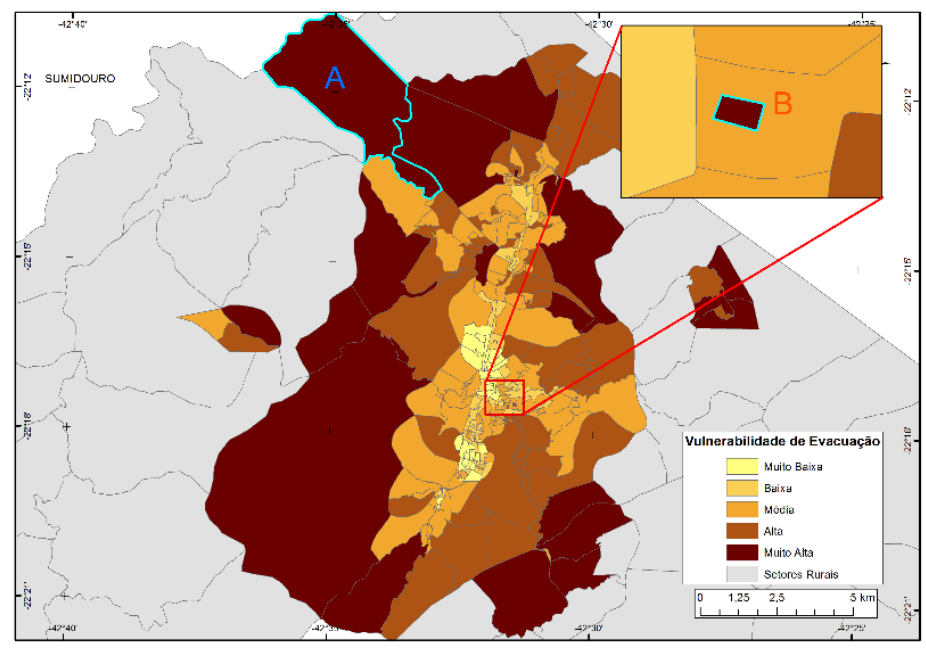

Fonte: Elaborada pelos autores.

Como pode ser visto, os dois setores selecionados estão em áreas bem diferentes e possuem tamanho e características também diferentes. O setor A possui maior dimensão e está no limite do município, em uma área mais periférica se comparada ao setor B, que está no centro da cidade e tem uma dimensão bem menor. Ao serem verificados os valores de IVE de cada um, é possível notar que apresentam valores semelhantes, mas a composição dos mesmos aponta para motivos diferentes. A Figura 11 apresenta o gráfico com os valores de cada indicador para cada um dos dois setores. 
Figura 11 - Gráfico com a composição do IVE para os setores com maior valor de vulnerabilidade de evacuação na área de estudo

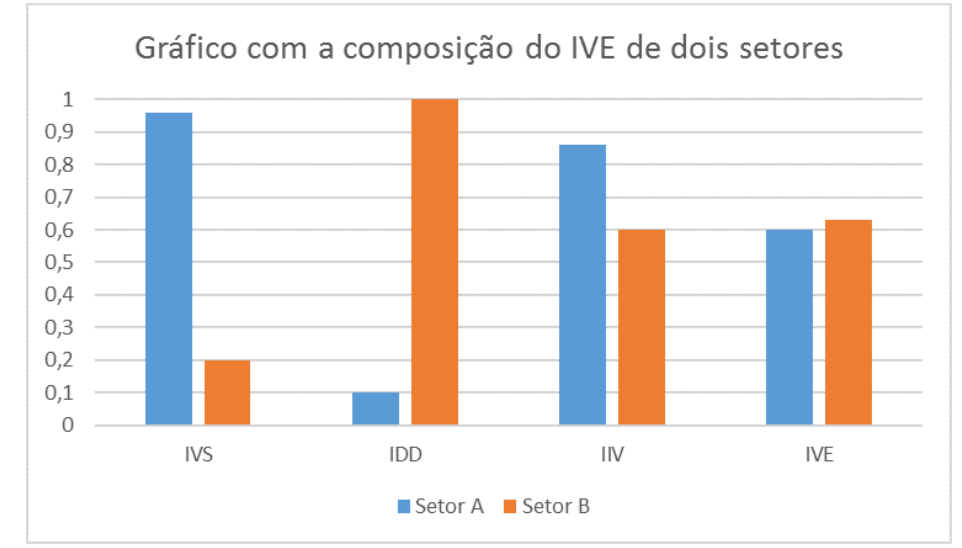

Fonte: Elaborada pelos autores.

É possível notar que o setor A possui uma vulnerabilidade social muito alta (IVS $=0,98$ ), apesar de sua muito baixa densidade demográfica (IDD = 0,1 ), além disso suas vias são muito pouco integradas (IIV $=0,86$ ). Já o setor $\mathrm{B}$, possui uma vulnerabilidade social baixa (IVS $=0,21$ ), tem a maior densidade demográfica da área de estudo (IDD = 1) e uma integração de vias média (IIV = 0,61). Com isso, o tratamento em cada um desses setores deve ser diferente, um com um foco nos problemas sociais apontados pelo IVS, o outro com a grande quantidade de pessoas em uma pequena área que não possui a melhor infraestrutura de vias integradas. Ter acesso por meio de uma base única de dados dos três indicadores é de essencial importância para o entendimento da vulnerabilidade de evacuação e de seus componentes, contribuindo para as decisões dos agentes públicos no que concerne a mitigação dos problemas encontrados.

Após a análise do resultado da aplicação do IVE, os resultados foram comparados entre a vulnerabilidade de evacuação com os dados referentes ao desastre de 2011. Os dados são os movimentos de massa mapeados e a infraestrutura do processo de evacuação representados pelos pontos de apoio e as sirenes do sistema de alerta. Isto foi feito no intuito de comparar o estudo e método proposto com o evento ocorrido e classificado como de extrema magnitude. 
Foram mapeados 368 escorregamentos, que se concentram na parte norte e noroeste da área de estudo, totalizando $5,4 \mathrm{~km}^{2}$ de área. Pode-se perceber também que alguns movimentos de massa ocorreram na região do centro da cidade, em áreas bastante densas de população. Nos setores classificados com vulnerabilidade de evacuação muito alta ocorreram 130 escorregamentos, com um total de $2,78 \mathrm{~km}^{2}$ de área, quase $51,5 \%$ do total dos movimentos. Quando somados os setores classificados como de alta vulnerabilidade de evacuação, $81,5 \%$ da área movimentada se encontram nestes setores.

Além da distribuição dos movimentos de massa pelos setores censitários, foi possível aplicar operações de geoprocessamento para identificar as vias que foram danificadas e que impediram ou dificultaram a movimentação de pessoas pela cidade. Do total de linhas axiais (7.679) do sistema representado, 696 foram afetadas por um ou mais escorregamentos. Ao se retirarem as linhas axiais afetadas foram aplicadas as regras topológicas, identificando 53 erros de linhas órfãs e 130 ilhas. Esses erros envolvem 3.140 linhas axiais que de alguma forma foram afetadas pelos movimentos de massa, caracterizam o nível de isolamento no pós desastre de diversas localidades na cidade.

A Figura 12 apresenta em vermelho as linhas axiais que foram afetadas pelos escorregamentos e em verde as que não foram, na porção oeste da área de estudo. É possível notar que algumas vias foram afetadas em mais de um ponto e outras áreas se desconectaram totalmente da trama urbana, criando áreas isoladas. Estes casos representam áreas da cidade que foram bloqueadas ou tiveram suas únicas saídas obstruídas por escorregamentos, dificultando o acesso por parte da gestão pública e a evacuação de pessoas. Este resultado aponta para a necessidade de serem avaliadas a implementação de medidas estruturais como: a construção de novas rotas alternativas; a instalação de heliportos para a retirada de pessoas por outros meios, que não as vias; alocação de recursos de limpeza e desobstrução de vias com tratores. Estas medidas devem ter como foco áreas caracterizadas por 
alta/muito alta vulnerabilidade de evacuação e/ou que possuam baixa integração de vias.

Figura 12 - Mapa com as linhas axiais afetadas e não afetadas pelos escorregamentos

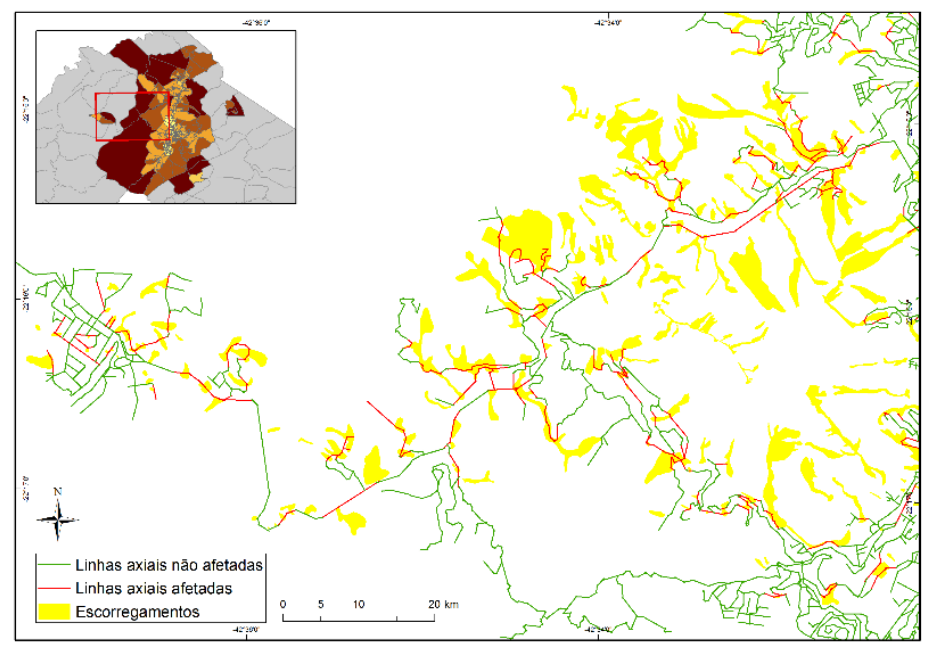

Fonte: Elaborada pelos autores.

O bairro de Córrego D'Antas é um dos exemplos de área bloqueada por escorregamentos. Este está no oeste da área de estudo e foi um dos locais com maior número de ocorrências de movimentos de massa na área de estudo. $\mathrm{O}$ bairro é cortado pela RJ-130, conhecida como TerêFri, que liga Teresópolis a Nova Friburgo, sendo ela sua principal forma de entrada e saída deste bairro. Na Figura 13 podem-se observar 64 escorregamentos mapeados e é possível notar que vários atingiram as vias (142 linhas axiais afetados em um total de 289). O bairro teve dificuldade para ser acessado pelo poder público e consequentemente teve também dificuldade para ser evacuado. Nota-se que, o mapeamento da vulnerabilidade de evacuação apontou a área como de alta e muito alta vulnerabilidade de evacuação. 
Figura 13- Mapa do bairro do Córrego Dantas atingido por inúmeros movimentos de massa e com IVE com valores de alta vulnerabilidade

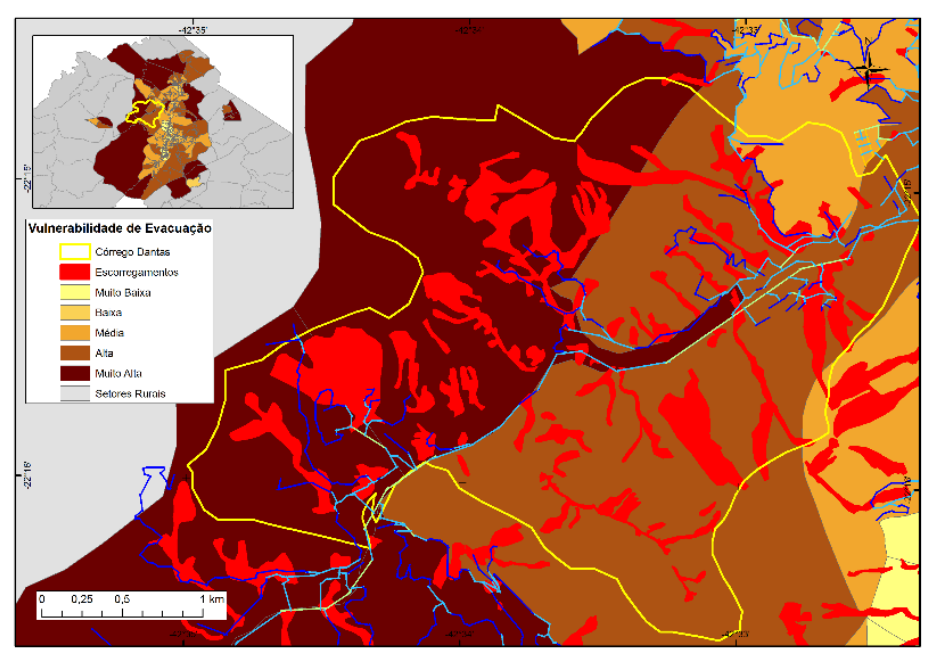

Fonte: Elaborada pelos autores.

\section{Conclusões}

A presente pesquisa buscou desenvolver uma metodologia com objetivo de identificar, caracterizar e mapear o perfil da vulnerabilidade de evacuação de áreas urbanas. Não teve por pretensão aprofundar a discussão teórica sobre o tema da vulnerabilidade. Os resultados desta pesquisa servem de subsídios a várias análises a respeito da vulnerabilidade e a tomada de medidas preventivas, como o planejamento da evacuação municipal em caso de desastres naturais, no que envolve a distribuição de recursos necessários para a evacuação, criação de pontos de apoio e rotas de fuga.

Os mapas dos indicadores das três dimensões que compõem a vulnerabilidade de evacuação permitem que sejam identificados o padrão espacial e a quantificação dos setores censitários e das populações mais vulneráveis frente à necessidade da realização de uma evacuação.

Pela característica do método estas análises podem ser feitas tanto por cada fator, utilizando seu respectivo indicador (IVS, IDD e IIV), quanto em conjunto, pelo indicador composto IVE, resultante da combinação dos outros três. Pelas características da vulnerabilidade de evacuação foi necessária a 
utilização da tecnologia SIG para o seu mapeamento, pois essa permite a manipulação de dados e informações das mais variadas fontes e formatos, inerentes a natureza dos estudos sobre vulnerabilidade. A produção de um único banco de dados contendo as informações que resultam na vulnerabilidade de evacuação facilita a comparação de diferentes unidades de análise em uma mesma cidade, auxiliando a tomada de decisões.

A metodologia obteve como principais resultados referentes às características sociais a observação de padrões de maior qualidade de acesso a serviços e menor exposição física nas áreas centrais da cidade de Nova Friburgo, ao passo que a vulnerabilidade social tende a aumentar quando se distancia dos fundos de vale e se orienta para áreas mais periféricas. Ao contrário disto, está a densidade demográfica, que apresenta maiores valores nas áreas centrais, caracterizando áreas de prioridade de ação no que tange o número de pessoas a serem evacuadas.

Em relação à integração das vias, pode-se notar que as vias mais acessíveis estão no centro da cidade. Poucas vias possuem essa característica, uma vez que para o universo de vias estudadas, 80\% delas encontram-se com os menores valores de integração. Isto permite uma avaliação sobre a forma da cidade de Nova Friburgo, que por suas características históricas de ocupação dificultam a movimentação de pessoas.

O mapa do IVE apresenta mais uma vez um padrão centro-periferia em relação às dificuldades observadas para a realização da evacuação de pessoas. O centro possui as melhores condições e a periferia as piores. As áreas mapeadas como de maior vulnerabilidade de evacuação coincidem com 81,5\% dos movimentos de massa ocorridos no em 2011, comprovando a importância e necessidade de dados que apontassem o grau de exposição e de dificuldade de evacuação de pessoas naquela ocasião.

O modelo pode e deve ser melhorado através da: incorporação de dados adicionais relativos às características físicas da região; de estudos mais detalhados do perfil socioeconômico da população em área urbana; de estudos sobre a cultura e percepção de risco com caráter mais aprofundado no 
comportamento humano; da assimilação das ações do poder público na gestão de desastres naturais; avaliação dos componentes que mais influenciam o processo de evacuação de pessoas; e desenvolvimento de software em plataforma livre para aplicação do método. O método utiliza o setor censitário como unidade de análise, outorgando a esta, limitações inerentes deste recorte espacial selecionado. Estas limitações estão associadas à homogeneização das informações, sejam elas sociais ou da integração das vias. Para maior aprofundamento do tema em relação a operação da evacuação seria interessante implementar a metodologia em unidades de análise menores que os setores censitários, como as faces de quadra e os cadastros de endereço.

A metodologia serve ao planejamento da evacuação, pois avalia e mapeia as áreas vulneráveis que necessitam maior atenção na aplicação de medidas satisfatórias pelos gestores públicos na redução de impactos e perdas humanas. Esta também pode ser adotada como um esforço inicial das Defesas Civis municipais ao avaliarem a vulnerabilidade de suas populações. Concluindo, para além do tema evacuação, os resultados obtidos a partir da aplicação da metodologia apresentam utilidade na orientação de políticas públicas em várias temáticas, com o uso dos indicadores parciais (IVS, IDD e IIV) e do indicador composto (IVE).

Por fim, vale ressaltar que o método proposto e os resultados obtidos não são definitivos. A identificação da vulnerabilidade de evacuação exige avaliação e monitoramento, sendo um processo contínuo que exige calibração do método e utilização de novas variáveis e técnicas e aplicação em outras áreas com diferentes características. 


\section{Contribuição dos autores}

O presente artigo é consequência direta da dissertação de Mestrado do autor Gustavo Medeiros de Pinho. A dissertação teve orientação direta dos Profs. Leonardo Castro de Oliveira e Marcos de Meneses Rocha. A Profa. Ana Paula Borba Gonçalves Barros teve contribuição focada no tema Sintaxe Espacial, tendo inclusive constituído a banca de defesa como membro externo. Durante a execução do artigo, coube ao autor Gustavo Medeiros de Pinho fazer o recorte e a formatação nas regras do periódico. Aos demais Profs., coube a função de verificar a fluidez do texto e realizar sua revisão.

\section{Referências}

ALBERICO, I.; PETROSINO, P.; MAGLIONE, G.; BRUNO, L.; CAPALDO, F.S.; DAL PIAZ, A.; LIRER, L.; MAZZOLA, S. Mapping the vulnerability for evacuation of the Campi Flegrei territorial system in case of a volcanic unrest. Natural Hazards, vol 10, n. 1, 2012. pp. 238-248

ALHEIROS, M.M.; BUITON, J.; SOUZA, M.; MEDEIROS, S.; AMORIM JÚNIOR, W. Manual de ocupação dos morros da região metropolitana de Recife, FIDEM/ATEPE. Recife, 2003. 384 p.

ANAZAWA, T.M., Vulnerabilidade e território no litoral norte de São Paulo: indicadores, perfis de ativos e trajetórias. Dissertação de Mestrado em Sensoriamento Remoto. Instituto Nacional de Pesquisas Espaciais, São José dos Campos, 2012. 190 p.

ARMESTO, R.C.G., Temas geológicos para educação ambiental, caderno IV ação da água das chuvas no planeta Terra parte II, CPRM, 2012. 41 p.

BARROS, A.P.B.G. Estudo exploratório da sintaxe espacial como ferramenta de alocação de tráfego. Dissertação de Mestrado. Universidade de Brasília, Programa de Pós-Graduação em Engenharia Civil e Ambiental, Brasília, 2006. $171 \mathrm{p}$.

BARROS, A.P.B.G. Diz-me como andas que te direi onde estás: inserção do aspecto relacional na análise da mobilidade urbana para o pedestre. 
Tese de doutoramento. Universidade de Brasília. Programa de Pós-Graduação em Transportes/Sistemas de transportes, Brasília, 2014. 372 p.

BLANKESPOOR, B., DASGUPTA, S., LAPLANTE, B., WHEELER, D. Adaption to climate extremes in developing countries: the role of education. Policy Research Working Paper. Washington DC: World Bank., 2010.

BRAGA, T.M., OLIVEIRA, E.L., GIVISIEZ, G.H.N. Avaliação de metodologias de mensuração de risco e vulnerabilidade social a desastres naturais associados à mudança climática. São Paulo em Perspectiva, vol. 20, n. 1, 2006. pp. 81-85 BRASIL. Lei $\mathrm{n}^{\circ}$ 12.608, de 10 de abril de 2012. Institui a Política Nacional de Proteção e Defesa Civil e dá outras providências. Brasília, Diário Oficial da União, 27 de novembro de 2012.

CÂMARA, G., MEDEIROS, J. S. Princípios básicos de geoprocessamento. In: ASSAD, E. D. \& SANO, E. I. (org.) Sistemas de Informações Geográficas. Aplicações na Agricultura. 2a . Edição revista e ampliada. Embrapa, 2003. pp. 3-13

CARVALHO, C.S., MACEDO, E.S., OGURA, A.T., Mapeamento de Riscos em Encostas e Margem de Rios. Brasília: Ministério das Cidades; Instituto de Pesquisas Tecnológicas - IPT, 2007.

CASTRO, A.L.C. Glossário de defesa civil estudos de riscos e medicina de desastres. Brasília, Ministério da Integração Nacional, Secretaria nacional de defesa civil, 2008. $174 \mathrm{p}$.

CONFALONIERI, U.E.C., BARATA, M.M.L., MARINHO, D.P. Vulnerabilidade climática no Brasil. In: CHANG, M. et al. (org.) Metodologias de estudos de vulnerabilidade à mudança de clima. Rio de Janeiro Ed. Interciência. 2015. pp. 23-38

COVA, T.J., CHURCH, R.L. Modelling community evacuation vulnerability using GIS. International Journal of Geographical Information Science, vol. 11, n. 8, 1997. pp. 76-784

DANTAS, M.E. Geomorfologia do Estado do Rio de Janeiro. In: CPRM-Serviço Geológico do Brasil. Estudo Geoambiental do Estado do Rio de Janeiro. Brasília, CPRM, 2001.

DOURADO, F., ARRAES, T. C., SILVA, M. F. O megadesastre da Região Serrana do Rio de Janeiro: as causas do evento, os mecanismos dos movimentos de massa 
e a distribuição espacial dos investimentos de reconstrução no pós-desastre. Anuário do Instituto de Geociências-UFRJ. v. 35, n. 2, 2012. pp. 43-54

DUARTE, F.R.P., Nova Friburgo: Um Estudo sobre a Identidade Urbanística. Dissertação de Mestrado. Universidade de Brasília, Programa de PósGraduação em Arquitetura e Urbanismo, Brasília, 2009. 213 p.

EKLUND, L., TELLIER, S. Gender and international crisis responde: do we have the data, and does ir matter? Disasters, v. 36, n. 4, 2012. pp. 589-608

GARCIA, M.L.T.; FRANCISCO, C.N. Métricas da paisagem no estudo da vulnerabilidade da Mata Atlântica na região serrana fluminense - Nova Friburgo, RJ. Anais do $\mathbf{1 6}^{\circ}$ Simpósio Brasileiro de Sensoriamento Remoto (SBSR), Foz do Iguaçu, 2013. pp. 3268-3274

GIL, J. Space Syntax Toolkit for QGIS, Version 0.1.0, Open Source, 2014 Disponível em: https:/github.com/SpaceGroupUCL/qgisSpaceSyntaxToolkit>. Acesso em: dezembro de 2015.

GIL, J.; VAROUDIS, T.; KARIMI K.; PENN, A. The space syntax toolkit: Integrating depthmapX and exploratory spatial analysis workflows in QGIS. 10th International Space Syntax Symposium, Londres, 2015. pp. 148:1-12

HILliER, B., HANSON, J. The Social Logic of Space. Londres: Cambridge University Press, 1984. 292 p.

HILLIER, B. Space is the machine. London: Cambridge University Press, 1996. $368 \mathrm{p}$.

HOLANDA, F. O espaço de exceção. Brasília: EdUnB, 2002. 466 p.

IBGE - INSTITUTO BRASILEIRO DE GEOGRAFIA E ESTATÍSTICA. Censo Demográfico 2010. Disponível em: http://www.ibge.gov.br/home/estatistica/populacao/censo2010/default.

Acessado em novembro de 2017.

IBGE - INSTITUTO BRASILEIRO DE GEOGRAFIA E ESTATÍSTICA. Base territorial: manual da base territorial 2014. Rio de Janeiro: IBGE, 2014. $157 \mathrm{p}$.

IBGE - INSTITUTO BRASILEIRO DE GEOGRAFIA E ESTATÍSTICA. Base de Faces de Logradouros do Censo 2010. Rio de Janeiro: IBGE, 2016. Disponível em: 
ftp://geoftp.ibge.gov.br/recortes_para_fins_estatisticos/malha_de_setores_cens itarios/censo_2010/base_de_faces_de_logradouros>. Acesso: julho de 2016.

JAFARI, M.; BAKHADYROV, I.; MAHER, A. Technological advances in evacuation planning and emergency management: Current stat of the art. Final Research Reports. Center for Advanced Infrastructure and Transportation, The State University Rutgers, 2003. 42 p.

LIU, X. YUE, Z.Q., THAM, L.G., LEE, C.F. Empirical assessment of debris flow risk on a regional scale in Yunnan Province Southwestern China. Environmental Management. vol. 30, n. 2, 2002. pp. 249-264

MARANDOLA, E.J, HOGAN, D.J. Vulnerabilidades e riscos: entre geografia e demografia. Revista Brasileira de Estudos Populacionais, São Paulo, vol. 22, n. 1, 2005. pp. 29-53

MEDEIROS, V.A.S. Urbis Brasiliae ou sobre cidades do Brasil. Tese de doutoramento. Universidade de Brasília, Programa de Pesquisa e PósGraduação da Faculdade de Arquitetura e Urbanismo, Brasília, 2006. 520 p.

MIRANDOLA, F.A., MACEDO, E.S. Proposta de classificação de tecnógeno para uso no mapeamento de áreas de risco de deslizamento. Quaternary and Environmental Geosciences. vol. 5, n. 1, 2014. pp. 66-81

NEUMAYER, E., PLÜMPER, T., The gendered nature of natural disasters: the impacto $f$ catastrophic events on the gender gap in life expectancy, 1981-2002. Annals of the Association of American Geographers. vol. 97, n. 3, 2007. pp. 551-566

SAITO, S.M., Dimensão socioambiental na gestão de risco dos assentamentos precários do Maciço do Morro da Cruz, Florianópolis SC. Tese de doutoramento. Universidade Federal de Santa Catarina, Programa de Pós-Graduação em Geografia, 2011. 253 p.

SANTOS, A. R. A grande barreira da Serra do Mar: da trilha dos Tupiniquins à Rodovia dos Imigrantes. São Paulo: O Nome da Rosa, 2004. 128p.

SENA, J.A., Análise integrada da vulnerabilidade na Amazônia Ocidental. In: CHANG, M. et al. (org.) Metodologias de estudos de vulnerabilidade à mudança de clima. Rio de Janeiro Ed. Interciência, 2015. pp. 127-152

STRIESSING, E., LUTZ, W. PATT, A.G., Effects of educational attainment on climate risk vulnerability. Ecology and Society, vol. 18, n. 1, 2013. 16 p. 
SZLAFSTEIN, C. Metodologia de análise e mapeamento de vulnerabilidade na Amazônia. In: CHANG, M. et al. (org.) Metodologias de estudos de vulnerabilidade à mudança de clima. Rio de Janeiro Ed. Interciência, 2015. pp. 180-125

TORRES, H.G. A demografia do risco ambiental. In: TORRES, H.G., COSTA, H. (org.) População e meio ambiente: debates e desafios. São Paulo: Senac, 2000. pp. $53-73$

TURNER, A. Depthmap 4: A Researcher's Handbook, Bartlett School of Graduate Studies, UCL, London. 2004.

UNITED NATIONS, UN. Sendai Framework for Disaster Risk Reduction 20152030. Third United Nations World Conference on Disaster Risk Reduction Sendai, Japan, 2015.

WAMSLER, C., BRINK, E., RENTALA, O. Climate change, adaptation and formal education: the role of schooling for increasing societies, adaptative capacities in El Salvador and Brazil. Ecology and Society, vol. 17, n. 2, 2012.

WISNER, B., BLAIKIE, P., CANNON, T., DAVIS, I. At risk: natural hazards, people's vulnerability and disasters. $2^{\circ} \mathrm{ed}$. London; New York: Routledge, 2004. $134 \mathrm{p}$.

WISNER, B., Vulnerability. International Encylopedia of Human Geography, 2009. pp. 176-182 